\title{
Experiência da pedagogia freiriana na região rural do município de Coimbra (Portugal, 1970)
}

Experience of Paulo Freire's pedagogy in the region of rural municipality of Coimbra (Portugal,1970)

\author{
Luís Alcoforado \\ Sónia Mairos Ferreira \\ Universidade de Coimbra
}

\section{Resumo}

No início da década de setenta do século XX, em pleno regime do Estado Novo, o Graal, um movimento internacional de mulheres católicas, desenvolveu um conjunto de atividades educativas na região rural do município de Coimbra, utilizando pela primeira vez, em Portugal, um programa planeado e desenvolvido de acordo com o pensamento e a experiência educativa de Paulo Freire.Este artigo pretende revisitar essas experiências de alfabetização, pós-alfabetização e animação social, utilizando os documentos produzidos pelo movimento, que suportavam teoricamente as intenções da sua intervenção social, os materiais produzidos para servirem de base ao desenvolvimento do programa e as memórias atuais de pessoas que vivenciaram essas experiências. Procura-se compreender a importância que, a esta distância temporal, as pessoas ainda atribuem a estas atividades incomuns, constatando-se o reconhecimento de um inegável impacto positivo nas pessoas e comunidades envolvidas.

Palavras-chave: Alfabetização. Animação social. Método Paulo Freire. Memórias educativas.

\section{Abstract}

In the early seventies of the twentieth century, in the regime of Estado Novo, the Graal, an international movement of Catholic women, developed a set of educational activities in the rural area of the municipality of Coimbra, using, for the first time in Portugal, one program planned and developed in harmony with the thinking and educational experience of Paulo Freire. This article aims to revisit these experiences of literacy, post-literacy and social animation, using the documents produced by the movement, which theoretically supported the purposes of its social intervention, the materials produced to serve as the basis for the development of the program and the memories of people who lived those experiences. We seek to understand the importance that, at this temporal distance, people still attribute to these uncommon activities, and acknowledge the recognition of an undeniable positive impact on the people and communities involved.

Keywords: Literacy. Social animation. Paulo Freire's Method. Educational memories. 
A primeira constatação que se poderá fazer, a partir da situação da escolarização e da alfabetização, em Portugal, ao longo dos últimos dois séculos e meio, é a de um atraso recorrente e acumulado, em relação à generalidade dos restantes países da Europa. Candeias, Paz e Rocha (2004, p. 40), num estudo comparado sobre os índices de alfabetização contidos nos sucessivos censos populacionais, desde final do século dezanove até aos últimos dados relativos ao século vinte, retiram uma primeira conclusão, que traduz a dimensão dessa diferença: "[...] a sociedade portuguesa entra no século XXI com taxas de alfabetização semelhantes àquelas com que as regiões do Norte e do Centro da Europa entram no século XX."

Esta situação, que representa, na objetividadepossível das estatísticas, um atraso de cem anos, resulta de uma dupla dificuldade: em primeiro lugar, da completa incapacidade para, durante mais de dois séculos, garantir o acesso à escola para todas as crianças; em segundo lugar, da recorrente tibieza com que (não) foi assumida uma política pública de Alfabetização e Educação de Adultos, resultando numa absoluta inépcia para implementar grandes campanhas de Alfabetização, como aconteceu noutros países europeus, ou para estruturar e estabilizar as políticas públicas necessárias a uma 60 oferta educativa para pessoas adultas, capaz de envolver todos os cidadãos.

Como fazem notar Ruas (1978) e Patrício (1982) este imobilismo de práticas e resultados acontecia, apesar de um conjunto regular e sistemático de iniciativas políticas e legislativas e do aparecimento e produção, ao longo dos sucessivos tempos e de diferentes regimes políticos, de um pensamento educativo atualizado e problematizador. Na verdade, é muito frequente encontrar, ao longo da Monarquia Liberal, textos de reformas educativas e de iniciativas não-governamentais, que traduzem um "esforço autêntico" para pensar, organizar e realizar a educação e instrução do povo português, sendo certo que "[...] se pensou mais e melhor do que se executou." (PATRÍClO, 1982, p. 49).

Também a Primeira República assumiu a educação, em geral, e a Alfabetização, em particular, como uma das suas principais causas. No entanto, apesar de um número não despiciendo de iniciativas inovadoras e das intenções de uma reforma geral do ensino, publicada em 1911, a promessa da República acaba por anoitecer "[... no crepúsculo da degradação política e da derrota, sem ter podido frutificar [...]" (PATRÍCIO, 1982, p. 65), ficando um conjunto bem-intencionado de fórmulas, transpirando um "eticismo 
voluntarista", numa "[...] lei marcada por um ideal patriótico e humanitário." (GRÁClO, 1981 , p. 397).

Apesar de procurarem manter o interesse pela instrução e educação popular, ainda que com motivações políticas bem diferentes, as primeiras iniciativas do Estado Novo, ao longo da década de trinta do século XX, revelaram-se algo contraditórias. Se, por um lado, resultou notória uma aposta no incremento do número de escolas e da sua frequência, prosseguindo o esforço de fazer chegar os benefícios da educação a todas as crianças, por outro lado assistiu-se a uma gradual descida do nível do ensino primário, resultante de um completo desinvestimento na preparação dos professores, uma vez que as escolas normais existentes foram encerradas. (RUAS, 1978). Muito clara era a marca e orientação ideológica que o novo regime procurava imprimir. Como faz notar Carvalho (1986), na reforma de 1936, protagonizada pelo ministro Carneiro Pacheco, era evidente o significado político queteve a mudança de nome do Ministério da Instrução Pública, para Ministério da Educação Nacional, correspondendo, esta alteração, de facto, à substituição da centralidade da Alfabetização, como era entendida pela I República, por uma ideia mais vasta e política de educação, colocada ao serviço dos valores do novo regime.

Uma leitura semelhante é igualmente válida para os restantes níveis e vias de ensino (CARVALHO, 1986), já que um aumento do número de liceus e de escolas técnicas não terá sido acompanhado pelo reforço da qualidade do ensino que aí se ministrava. Assim sendo, Portugal chega ao fim da II Guerra Mundial numa situação assaz grave, no que à educação e alfabetização da população dizia respeito. Em face desta situação, dos alinhamentos e compromissos políticos e económicos internacionais e das necessidades resultantes das migrações internas e externas, o Estado Novo empreende, na primeira metade dos anos cinquenta, um conjunto de iniciativas com impacto significativo, quer na escolarização, quer na Alfabetização de Adultos. Aliás, no dizer de Ruas (1978, p. 290), nesta época, foi desencadeado, "[...] pela primeira vez, no país, um processo verdadeiramente eficaz de Educação de Adultos."

Neste âmbitofoi promulgado o Decreto-Lei n 38 968, de 27 de outubro de 1952, o qual, procurava instituir, em simultâneo, a efetividade da frequência escolar para todas as crianças e um projeto de Educação de Adultos, que incluísse, não só um esforço significativo de alfabetização, mas abrangesse um conjunto mais alargado de ações educativas, até porque "[...] 
uma política de educação popular não pode propor-se apenas divulgar os conhecimentos das primeiras letras, mas ainda, e na medida do possível, valorizar e completar a formação moral e espiritual do nosso povo." (DECRETO-LEI No 38968 DE 27 DE OUTUBRO DE 1952).

No que diz respeito à Educação de Adultos, o empenho foi significativo, pensando, particularmente, no milhão de adolescentes, jovens e adultos, entre os catorze e os trinta e cinco anos, que eram analfabetos, 0 Plano contemplava, sobretudo, uma campanha nacional contra o analfabetismo, designada "Campanha Nacional de Educação de Adultos" que visava "[... es essencialmente a preparação para o exame do ensino primário elementar de analfabetos [...]" (RUAS, 1978, p. 291), devendo os programas seguir os da instrução primária elementar, procurando-se, também, divulgar noções de educação moral e cívica, organização corporativa, previdência social, segurança no trabalho, higiene e defesa da saúde, agricultura e pecuária.

Se a generalidade dos autores concorda com uma leitura positiva do impacto da campanha, que poderá ter envolvido, segundo dados oficiais, cinquenta por cento da população alvo, alguns aspetos qualitativos levam-nos a temperar entusiasmos excessivos, principalmente no que diz respeito ao recurso 62 a métodos e conteúdos infantilizados e redutores e a uma planificação e organização completamente centralizada.(PATRÍCIO, 1982; CARVALHO, 1986).

Neste aspeto, as iniciativas da Campanha estavam já em completo contraciclo com as recomendações das organizações internacionais que promoviam reflexões sobre o desenvolvimento da Educação de Adultos, mas, apesar disso, o Plano de Educação Popular colocou alguma centralidade na importância da Educação de Adultos, permitindo, ao mesmo tempo a emergência de um outro conjunto de medidas e práticas, que não desdenharíamos interpretar como relativamente compaginadas com algumas das ideias mais inovadoras, não fosse a omnipresente e opressiva dimensão política e axiológica do regime vigente.

Para além desta iniciativa, as décadas de cinquenta e sessenta acabaram por ver surgir, também em consequência da Campanha Nacional de Educação de Adultos (RUAS, 1978), um conjunto de dinâmicas governamentais (distribuídas por diversos ministérios) e não governamentais (Obra das Mães, Liga Agrária Católica e Graal, por exemplo), que foram mantendo a preocupação de uma ação educativa militante e indispensável, para diferentes 
públicos, em diferentes contextos, mormente nas zonas rurais e do interior, onde apenas se tinham sentido efeitos muito ténues do esforço oficial da Campanha.

A ação do Graal, mormente a que foi desenvolvida na região rural do município de Coimbra, já no primeiro ano da década de setenta, configurou uma experiência, a todos os títulos, inovadora. Pela primeira vez' é utilizado, em Portugal, ao longo de todo o processo, desde o planejamento à preparação das equipas e às atividades, o pensamento e a experiência educativa de Paulo Freire, dando lugar ao desenvolvimento de um conjunto de práticas que, pelo tempo e espaço em que decorreram, merecem uma análise compreensiva circunstanciada. É isso que nos propomos fazer no presente. Utilizaremos, numa primeira fase, os documentos produzidos pelo movimento e suas associadas, procurando compreender os seus objetivos, valores e razões para um envolvimento nestas atividades educativas. Depois iremos debruçar-nos sobre os materiais produzidos para servirem de base ao desenvolvimento do programa, procurando entender a utilização do pensamento do grande pedagogo brasileiro naquelas iniciativas. Por fim, registaremos memórias de pessoas que vivenciaram essas experiências, visando compreender a importância que a esta distância temporal elas ainda têm para as suas vidas pessoais e comunitárias. A partir dos documentos de suporte à intervenção e de fotografias das atividades desenvolvidas na freguesia de Almalaguês, foi possível identificar quatro pessoas envolvidas, às quais pedimos que desfiassem as suas recordações dos momentos vividos. Associando, desta forma, uma detalhada análise documental com os testemunhos, emitidos quarenta e dois anos depois, por quem se envolveu numa experiência inusitada, procuraremos sintetizar o impacto que a primeira utilização dos contributos de Paulo Freire teve em comunidades rurais do Portugal, de inícios dos anos setenta do século XX. Contamos, para este trabalho de pesquisa, com a participação de quatro pessoas que viveram estas experiências: três delas estiveram envolvidas nas atividades de pós alfabetização e de animação social e uma apenas nestas últimas iniciativas. Optamos por basear este artigo, de forma predominante, nas memórias das três pessoas que viveram os dois tipos de experiências. 


\section{Novas propostas: o Graal e a necessidade de uma intervenção social e comunitária}

Graal começou a sua ação em Portugal no final da década de cinquenta do século XX, por iniciativa de duas jovens empenhadas nos movimentos católicos universitários. A primeira dessas jovens, Maria de Lurdes Pintassilgo, teve o primeiro contato com o movimento no seu centro internacional, em Tiltenberg, na Holanda, enquanto a segunda, Teresa Santa Clara Gomes, foi envolvida pelos seus ideais num encontro desenvolvido em Grailville, centro nacional nos Estados Unidos. . A convicção conjunta transparecia na perceção de que tinham encontrado a resposta para o "[...] desejo fortemente sentido, por grupos de estudantes católicos, de uma vivência cristã, integradora de novas dimensões", entre as quais avultavam [...] "[...] a liturgia celebrada com profundidade e beleza e a reflexão sobre a especificidade do ser e do agir das mulheres." (GRAAL, 1983, p. 5).

Após algumas experiências políticas, ao longo dos anos setenta, a primeira das fundadoras chegou a exercer, no final da década, por um período de noventa dias, o cargo de Primeira-ministra de Portugal. Esse facto veio 64 renovar uma curiosidade natural sobre o seu percurso e, principalmente, a atividade do movimento que the tinha dado particular notoriedade. Sentindo a oportunidade de se tornar mais conhecido e a necessidade de revelar o essencial da sua identidade e ação, o Graal dedicou um número do seu boletim a essa tarefa. (GRAAL, 1979, p. 1). Aí, assume-se como um Movimento Internacional de Mulheres Cristãs que se apresenta como uma multiplicidade de fórmulas: espaço de encontro e de procura; encruzilhada de reflexão crítica; lugar de empenhamento; plataforma de ação/reflexão; laboratório de inovação. Ao percorrer aquele exercício descritivo de autoanálise, ficamos a saber mais sobre as suas filiadas e os seus objetivos:

Integrado por mulheres de diferentes culturas, idades e situações de vida, jovens e adultas, casadas e solteiras, trabalhadoras em meio rural e meio urbano, recém-alfabetizadas e intelectuais... o que as une? Como perguntaram as estudantes da Universidade de Nimegue que iniciaram o movimento, em 1921, o que as lançava na procura do Graal? A meta permanece a mesma, trata-se de olhar as mulheres como uma nova força social, capaz de contestar, subverter e inovar, e de assim contribuir para a mudança qualitativa da vida em sociedade... se é preciso justificar o Graal 
diremos que a sua razão última de ser é fazer emergir na vida de cada um a Boa Notícia ou a Boa Nova que o Evangelho de Jesus Cristo veio trazer. Ora essa notícia é, como sabemos, a promessa de uma nova terra. Para quê então o Graal, senão para desafiar as mulheres a participarem ativa e conscientemente na construção dessa nova terra? (GRAAL, 1979, p. 1).

A convicção mais profunda das suas associadas levava-as a acreditar que essa missão implicava uma ação no terreno, junto das pessoas e das comunidades. $\bigcirc$ desafio de participação nunca ficaria completo sem uma tomada de consciência que as levasse a assumir "[... ] um compromisso sério e pessoal com os mais desfavorecidos, com os pobres e oprimidos da sociedade portuguesa." Daí a opção por uma abordagem "[...] cada vez mais interveniente, motivada pela urgência de devolver ao povo a possibilidade de ser sujeito das suas próprias decisões, sujeito pleno da sua própria história." (GRAAL, 1983, p. 25 e 23). Movidas pelo desejo de contribuir para uma maior humanização da sociedade portuguesa, através de um projeto concreto assente em técnicas de desenvolvimento comunitário, já nessa altura muito divulgadas, acreditavamna "[...] ideia corrente na época de que a evangelização não é possível sem uma base de promoção humana."

Na verdade, a década de sessenta do século XX, em Portugal, é marcada pelo êxodo das populações rurais, ou para a emigração em direção a França e à Alemanha, ou para as grandes cidades do litoral, onde começavam a estruturar-se os primeiros movimentos de industrialização. Em entrevista concedida a António Teodoro, na década de noventa, Maria de Lurdes Pintassilgo recordava a sua experiência de engenheira química num dos maiores grupos da cintura industrial de Lisboa: "[... eu tinha vivido o desenvolvimento pela via da industrialização e vi que esse desenvolvimento estava incompleto, e que martirizava os homens - o seu preço social era insuportável." (TEODORO, 2002, p. 146). Apesar disso, tornava-se evidente que estes movimentos demográficos correspondiam à procura desesperada de uma vida melhor, abandonando as condições de grande pobreza, dos ambientes exclusivamente ligados à produção agrária. Tínhamos assim, em síntese, um país onde se mantinham inúmeras comunidades rurais em situação de reconhecida penúria e se iam acumulando comunidades suburbanas de novos trabalhadores da indústria, que experienciavam condições sociais e profissionais muito pouco humanizadas. (BARRETO; PRETO, 2000). De comum, todas tinham uma 
expectativa de vida muito determinada por condições políticas repressivas e culturalmente condicionadas².

Acreditando, então, que o movimento tinha que responder às necessidades de cada lugar e cada comunidade e convictas que só na ação justificavam a sua existência, as "mulheres" do Graal envolvem-se num projeto de intervenção social, sentindo, tal como Paulo Freire nos descreve em Cartas a Cristina, que levar Cristo às pessoas e às comunidades obrigava a um empenhamento militante pela sua mobilização em prol de uma vida mais digna.

Outro aspeto fundamental dos programas era a ligação do cultural com o político. Como os encontros sobre os assuntos políticos eram formalmente proibidos, servíamo-nos do contexto das nossas atividades, enquanto grupo católico, para os integrar. Falávamos de justiça social e de socialismo; denunciávamos o que na sociedade portuguesa era contrário à dignidade humana e aos valores do Evangelho, procurávamos anunciar vias e perspetivas para que o 'novo' pudesse acontecer. Basta lembrar, no Inverno de 1969, a discussão à volta de "O Pomar de Cerejeiras" de Tchekov e de ' $\mathrm{O}$ Círculo de Giz Caucasiano' de Brecht. No repetir, como simples evidência, a frase de Brecht 'o vale pertence a quem o souber fazer florir' apontávamos, já então, para o país que queríamos construir: um país sem desigualdades nem descriminações, um país onde a riqueza fosse de todos e para todos. (GRAAL, 1983, p. 19).

$\bigcirc$ facto de se tratar de um movimento de mulheres católicas trazia vantagens e inconvenientes, à atividade do Graal. Por um lado, podiam utilizar alguma imunidade, que a concordata thes garantia, para se envolverem em ações que noutros enquadramentos seriam, sempre, proibidas pela ditadura. Por outro lado, ficando muito dependente da aceitação da hierarquia da lgreja, acabava por ficar exposto à avaliação algo arbitrária, em cada momento, dos bispos da diocese em que as atividades eram, ou pretendiam ser, desenvolvidas. Assim, perante a recusa do Cardeal Patriarca de Lisboa em aceitar a sua atividade na região da capital, no início da década de sessenta, o movimento tentou espaços de ação noutras comunidades, sob a égide de outros bispos. Após alguns contactos e negociações, o Graal acaba por se instalar nas dioceses de Portalegre e Coimbra ${ }^{3}$. Nesta última cidade vem encontrar um ambiente universitário em efervescência, propício a novos 
debates e disponível para todas as mudanças que a generosidade de uma militância católica progressista convocava.

Fiéis ao compromisso de se envolverem na promoção de processos transformativos em comunidades socialmente mais desfavorecidas, em 1968, nos arredores de Coimbra, o movimento desenvolveu - com a participação da Universidade de Roma - o projeto Sociologia Participada, o qual se apresentava como "[...] um trabalho de investigação/ação que visava devolver às comunidades locais o conhecimento da sua própria realidade para que sobre ela pudessem exercer um juízo crítico e atuante." (GRAAL, 1983, p. 24). Apesar da adesão das populações, o projeto confrontou-se com a dificuldade dificilmente ultrapassável, por falta de recursos, de responder às aspirações que ele próprio motivava.

Momento seguinte registouum forte empenhamento em atividades de alfabetização de adultos. Esta iniciativa concitava, ao mesmo tempo, os talentos de jovens universitárias para o ensino da leitura e da escrita a pessoas que não tinham frequentado a escola, ou a tinham abandonado muito precocemente, por manifesta inadequação, ou falta de recursos, e procurava disponibilizar as ferramentas indispensáveis para uma maior participação social. Após umas primeiras iniciativas que decorreram em Portalegre, em Coimbra, no verão de 1970, foi desenvolvido o "momento mais alto" destas atividades de alfabetização, "[...] envolvendo quarenta estudantes, divididos em três equipas, os quais animaram cerca de vinte grupos de adultos, a partir das aldeias do Dianteiro, Cabouco e Almalaguês." (GRAAL, 1983, p. 26). Foi este programa que, integrando iniciativas de alfabetização, pós-alfabetização e animação social, se constituiu como a primeira experiência educativa, desenvolvida em Portugal, com baseno pensamento e nas experiências desenvolvidas por Paulo Freire. Vale a pena, por isso, perceber as dimensões teóricas e metodológicas que o enquadraram.

\section{Paulo Freire no Portugal de 1970 por iniciativa do Graal}

Um quarto de século após o desenvolvimento deste programa, Maria de Lurdes Pintassilgo encontrava uma justificação muito simplespara a convicção que o motivou: "[... ] nessa época eu tinha a noção de que a educação de adultos era o ponto-chave (para a mudança) numa sociedade como a nossa." 
(TEODORO, 2002, p. 149). No entanto, a história da educação em Portugal, mormente da educação de adultos, e as experiências educativas desenvolvidas pelo Graal, ao longo da década de sessenta, aconselhavam a procura de novas soluções, impelindo à descoberta de respostas que associassem as dimensões social e educativa. Mais que aprender a ler e a escrever, ou criar condições para a elevação dos níveis de escolaridade das populações, era necessário que elas sentissem a importância que essas novas ferramentas podiam desempenhar na construção de uma vida melhor, a partir das necessidades que elas próprias sentissem. É esta busca que leva a Paulo Freire!

Socorrendo-nos, mais uma vez, da entrevista da Presidente do Graal, podemos constatar a segurança das novas orientações pedagógicas. "Nos anos 60 Paulo Freire esteve na Europa. As minhas amigas de outros países trabalhavam com ele, em diferentes formas de conscientização. Senti então que era necessário fazer um trabalho claramente social "[...] começamos a desenvolver trabalho no campo da alfabetização, do movimento comunitário, tudo aquilo que naquela época eram realmente os elementos para o desenvolvimento." (TEODORO, 2002, p. 146). No balanço sobre os seus primeiros vinte e cinco anos de atividade em Portugal, o movimento reconhece a impor-

68 tância que esta inflexão de práticas passou a desempenhar. "Paulo Freire e a sua pedagogia tiveram uma influência decisiva na nossa ação e interpretação dos acontecimentos. Os seus conceitos e a sua metodologia influenciaram grandemente muitos dos nossos projetos." (GRAAL, 1983, p. 26).

A pergunta mais imediata que resulta desta leitura será a seguinte: que interpretação e que utilização dos trabalhos de Paulo Freire foi apropriada pelo Graal? Percorrendo os documentos preparativos da ação constatamos primeiro, uma síntese elaborada pela equipa técnica do movimento (GRAAL, 1970) dos livros Educação como Prática de Liberdade, Intrducción a la acción cultural e Pedagogy of the opressed, depois, uma leitura comentada do IV capítulo do livro Educação como prática de liberdade e por fim, um conjunto de guiões destinados à formação dos alfabetizadores e animadores, para servir de quadro teórico para as atividades educativas. Em Educação como prática da liberdade Paulo Freire advoga uma educação para a liberdade em busca da humanização do homem via conscientização psicopedagógica, sendo, principalmente, estas preocupações que ressaltam nas notas de leitura e no documento de formação. Nosapontamentos manuscritos pode constatar-se o realce concedido a uma "posição filosófica existencialista" e à valorização 
de uma "[...] teoria da linguagem como expressão de realidade criadora", enquanto nostextos se afirma que" [...] uma das constatações das práticas pedagógicas de Paulo Freire é a de quetoda a animação (ação cultural) coloca desafios ao homem, objetivando a sua situação existencial e [...] na medida em que o homem responde aos desafios, ele produz a sua cultura lentendida como resultado de toda a ação humana) e transforma o mundo". (GRAAL, 1970, s/p.).

É, pois, no assumir de uma conceção de Homem como sujeito da produção cultural, centro de decisão e agente do processo histórico que este conjunto de atividades se estrutura. Neste sentido, a educação e a ação cultural assumem uma dimensão política total de compromisso com o envolvimento de homens e mulheres na assunção do seu papel central de decisores, na construção de novas comunidades e nova sociedade. No documento preparatório podemos encontrar a identidade pedagógica do programa de intervenções, através do seguinte conjunto de proposições interrelacionadas: o homem cria cultura; o homem escreve a história; então tem necessidade de uma pedagogia que em vez de o ajustar, de o domesticar, e de o tornar escravo, seja capaz de o transformar em homem livre. Esta é a caraterização central que o grupo faz do pensamento educativo de Paulo Freire. Sobre a dimensão metodológica também não se vislumbra que subsistissem dúvidas de maior. Os principais pilares constitutivos da intervenção eram, então, a passagem da consciência intransitiva para uma consciência transitiva critica como forma de transformar as pessoas envolvidas em sujeitos e o diálogo como meio de conhecimento. (GRAAL, 1970, s/p).

Justificada a necessidade do programa de ações com estas dimensões ideológica e metodológica iniciou-se a sua operacionalização, com a preparação da equipa de alfabetizadores e animadores, numa Semana de Orientação, destinada a envolver os participantes num conjunto de atividades formativas designadas como Estágios de Alfabetização e Animação Social, segundo a metodologia de Paulo Freire ${ }^{4}$. Para além das dirigentes do Graal e dos futuros alfabetizadores e animadores, as atividades do estágio contaram com a participação de docentes da Universidade de Coimbra ${ }^{5}$ e assumiam, logo na apresentação do programa, os seguintes objetivos gerais:

- $\bigcirc$ estabelecimento de uma interação dinâmica entre rurais e universitários, em ordem a um mútuo conhecimento e a uma experiência válida de cooperação e trabalho de equipa. 
- A reflexão conjunta sobre a situação de vida das comunidades daquela regiãob, em ordem a uma tomada de consciência crítica sobre os obstáculos e possibilidades que se apresentam ao progresso e à valorização humana.

- A descoberta das capacidades reais de criação e transformação que existem nos indivíduos e nas comunidades daquela região. (GRAAL, 1970, grifo do texto).

Pensado como um tempo de equilíbrio entre ação e reflexão e destinado a uma identificação com a pedagogia de Paulo Freire, aceite como aplicável a ações de alfabetização, pós-alfabetização e animação social, o programa estava pensado para articular momentos de confronto de ideias, em Coimbra, e partilha de vida nas comunidades rurais, estruturando-se em sessões que decorriam em três períodos do dia: manhã, tarde e serão. Do programa, para além dos momentos de síntese e de um primeiro tempo de prospeção das competências existentes no grupo, faziam parte conteúdos como Reflexão sobre o mundo rural e a sua cultura, O conceito de "cultura popular", Brainstorming sobre o conceito de "homem", Abordagem à Pedagogia de Paulo Freire, Brainstorming sobre as palavras geradoras, Considerações sobre 70 temas de política, Implicações da Pedagogia de Paulo Freire em diferentes situações, Geografia Humana da região de Coimbra, Atitudes para um bom acolhimento nas aldeias e Situação socioeconómica da região de Coimbra. No caso concreto das palavras geradoras, houve o cuidado de as escolher a partir, num primeiro momento, da promoção "[...] do conhecimento e contacto da equipa técnica com as aldeias e interesses e falares do povo [...]" e, num segundo momento, através de um trabalho de "[...] refinamento das palavras segundo um critério linguístico de complexidade crescente, feito por um especialista." (GRAAL, 1970, s/p). Foram, assim, encontradas dezassete palavras, organizadas em seis conjuntos, como se indica no Quadro 1. 
Quadro 1

Lista das 17 palavras geradoras, organizadas em 6 conjuntos

\begin{tabular}{|c|c|c|}
\hline $\begin{array}{c}\text { Rancho } \\
\text { Vinho }\end{array}$ & $\begin{array}{c}\text { Freguesia } \\
\text { Comissão }\end{array}$ & $\begin{array}{c}\text { Povo } \\
\text { Governo } \\
\text { Guerra }\end{array}$ \\
\hline $\begin{array}{c}\text { Trabalho } \\
\text { Fábrica }\end{array}$ & Escola & Tijolo \\
Enxada & Jornal & Saúde \\
Bicicleta & Praça \\
\hline
\end{tabular}

Fonte | GRAAL, 1970

Num dos textos de debate, destinados à formação dos alfabetizadores, intitulado Reflexão sobre o mundo rural e a sua cultura, da autoria de António Barbosa de Melo, pode ler-se que "[...] o homem não é um mero produto do sistema económico, é antes o autor da sua própria alienação, dispondo em si mesmo das forças de que há mister para se libertar dela." (GRAAL, 1970 , s/p). Muitas vezes, os homens e as mulheres necessitam de ajuda nestes processos de libertação, sendo essa a razão principal para se desenvolverem estas possibilidades de conscientização, resultantes da interação das pessoas dos meios rurais com os jovens estudantes universitários, vindos de ambientes urbanos. No mesmo texto, o mesmo elemento da equipa técnica enuncia, mais uma vez, as razões para recorrer ao pensamento de Paulo Freire:

A alfabetização, no sentido de Paulo Freire é, em tal ordem de ideias, um acto de conhecimento de uns tantos símbolos que permitem o domínio da escrita, mas é, sobretudo, um acto tão íntimo e pessoal do próprio sujeito cognoscente, que acaba por libertá-lo, de dentro, abrindo-the os olhos para a sua situação de "ser livre, mas atado por outro lado, aos grilhões da servidão" (Rousseau). (A alfabetização). É assim um acto constitutivo de liberdade, tão cívica quanto políica e, por isso, criador de um homem novo e de uma sociedade nova. (GRAAL, 1970, s/p., grifo do texto).

Sublinhando-se, no debate do grupo, o assumir de Paulo Freire da defesa em prol de uma radical igualdade entre todos os homens, não apenas no sentido iluminista da dignidade moral e cívica, mas principalmente da real capacidade criadora que os transforma em agentes do processo histórico, o 
debate sobre as palavras geradoras e o diálogo como processo transformador foi elevado a verdadeira pedra-de-toque de toda a dinâmica alfabetizadora. Ao afirmar-se que se considera o método como "tanto quanto possível, despido de adereços ideológicos", existe a convicção de se estar perante um processo político, criador de condições para uma efetiva mudança social não induzida do exterior e por quem vem de fora ${ }^{7}$. Usando uma das últimas expressões do documento de orientação, "[...] a conscientização não propõe um modelo dado de sociedade ou modelo político, esperando que o modelo venha a ser criado pelo povo; a conscientização não orienta para uma opção partidária prédefinida, encorajando um pluralismo de posições e opções." (GRAAL, 1970, $\mathrm{s}$ / p). Por outro lado, e por isso mesmo, as palavras geradoras foram também entendidas como temas geradores que deviam ser motivo de reflexão crítica, quer nos grupos de alfabetização, quer nos grupos de pós-alfabetização.

\section{Quadro 2}

Tipos de ação desenvolvidas, com os respetivos objetivos

\begin{tabular}{|c|l|}
\hline Aç̃es & \multicolumn{1}{|c|}{ Objetivos } \\
\hline Alfabetização & $\begin{array}{l}\text { - Ajudar os alfabetizandos a tomarem consciência das suas } \\
\text { capacidades de aprendizagem e criação, pela experiência } \\
\text { da aprendizagem activa da leitura e da escrita } \\
\text { • Fazê-los utilizar a comunicação escrita ou oral como meio } \\
\text { de alargamento do seu universo pessoal e instrumentos con- } \\
\text { ducentes a uma participação mais responsável na sociedade. }\end{array}$ \\
\hline Pós-Alfabetização & $\begin{array}{l}\text { - Ajudar os alfabetizados a tomarem consciência do carácter } \\
\text { dinâmico e permanente da aprendizagem, pondo-os em con- } \\
\text { tacto com novas extensões da sua experiência de vida que } \\
\text { constituem a chamada "matéria escolar". } \\
\text { - Prepará-los, a longo prazo, para as provas escolares - } \\
\text { exame de instrução primária - que lhes darão acesso a uma } \\
\text { maior promoção dentro do "sistema" social". }\end{array}$ \\
\hline Animação Social & $\begin{array}{l}\text { - Introduzir nas tarefas diárias e nas experiências diárias do } \\
\text { conjunto da população, ou de determinados sectores - crian- } \\
\text { cas, jovens, adultos - novas dimensões de conscientização e } \\
\text { criação cultural. }\end{array}$ \\
\hline
\end{tabular}

Fonte | GRAAL, 1970

Como já foi afirmado, a alfabetização era, apenas, uma das componentes das ações de intervenção a desenvolver com as populações da região. 
Acreditando que as propostas eram igualmente adequadas para atividades de pós-alfabetização e animação social, em qualquer uma das povoações envolvidas deveriam ser desenvolvidas estes três tipos de ação, com os objetivos que se indicam, para cada uma, no Quadro 2.

Após o período de Orientação, no dia oito de agosto, vinte e sete Animadores (oito para a Alfabetização, oito para a Pós-alfabetização e onze para a Animação Social) iniciaram a sua atividade nas localidades previstas, intercalando a sua ação educativa com reuniões locais de reflexão e encontros semanais, em Coimbra, com o objetivo de realizar balanços circunstanciados do trabalho realizado, prolongando a sua intervenção até 15 de setembro. No caso concreto de Almalaguês, que nos ocupará nos pontos seguintes, foram organizados um grupo de alfabetização com dez pessoas, três grupos de pós-alfabetização, envolvendo trinta pessoas, e três grupos de animação social com a participação regular de oitenta pessoas. Se no caso da pós-alfabetização houve, também, a preocupação de desenvolver um programa de preparação para a realização dos exames de final da escolaridade obrigatória, a animação social foi pensada para incluir ensino de francês, principalmente aos mais jovens, a preparação de pequenas atividades teatrais, encontros de mães, atividades recreativas para crianças e projeções de filmes com debates.

\section{Memórias da Escola da Amizade, quarenta e dois anos depois}

Inquiridos, quarenta e dois anos depois, acerca da sua recordação da ação do Graal, seria previsível, pelo hiato temporal em causa, que tivesse ocorrido esbatimento, ou mesmo extinção, das memóriasrespeitantes a uma parte substantiva das experiências que materializaram esta iniciativa pioneira, que decorreu noprincípio da década de 70 do século transato, numa das regiões com maiores traços de ruralidade do município de Coimbra. Igualmente expectável seria que as narrativas dos/asentrevistados/as se centrassem, quase em exclusivo, na descrição da sua própria experiência, nomeadamente através da identificação de situações de aprendizagem às quais associaram e, por ventura, ainda associam, maior significado ou a revisitação de momentos concretos que, a seu ver, espelham o seu envolvimento nela. Todavia, a concretização destas entrevistas, com a duração média de cerca de hora e meia, 
revelou que as memórias destes tempos e espaços estão muito vivas na mente dos/as entrevistados/as, os quais atribuem significado profundo à participação nestas ações e, naquele tempo e hoje, relevam as aprendizagens então realizadas como essenciais, não só para o seu desenvolvimento, mas, em estreita associação, para aevolução das comunidades a que pertenciam(em).

Perante a primeira questão, subordinada à evocação das recordações que mantinham desses tempos e contextos, os/as inquiridos/as rapidamente iniciaram uma narrativa densa e emotiva das experiências vivenciadas, a qual se sustenta numa recordação detalhada da riqueza e da especificidade da ação implementada e, também, sobre o seu papel nestas iniciativas.

Vou explicar o que foi e o que aconteceu, porque passou-se comigo, não é? Eu era uma jovem. Isto foi em 70, que eu conheci o graal aqui em almalaguês. Vinha aqui um grupo de estudantes, e era dirigido por uma senhora que ainda hoje é viva lá no graal, que é a T. A T. fazia a ligação com a Cáritas. A Cáritas emprestava o carro, para virem com os estudantes da academia, de várias Faculdades, que vinham aqui à noite, dar-nos as aulas e ela é que coordenava o programa todo, não é? Eramos muitos jovens. Na altura nós tiramos o que se chamava o segundo ano, se calhar agora tem outros nomes. Éramos uns vinte e tal jovens, fora isso os que estavam a aprender a ler e a escrever, e outros a tirar a quarta classe... E... Bem, era muita gente, e então eu comecei também a entrar, e entrei nesse grupo. (Al, 2012).

Recordaram, também, as interrogações iniciais que a participação nas ações do Graal colocou às mulheres e homens em Almalaguês, as quais foram rapidamente ultrapassadas, tendo sido envolvido um grupo de largas dezenas de pessoas. Apontaram, a este propósito, como fatores explicativos do incremento da participação da população nas iniciativas, a concretização de algumas sessões de discussão em grupo, que decorreram na praça da Aldeia, às quais se associou a presença repetida deste grupo de profissionais e voluntários no quotidiano de Almalaguês.

Eu nessa altura também estava assim duvidosa... Não sabia... Era um grupo de pessoas e elas começaram a fazer reuniões assim com o povo. Eu acho que na altura havia um grande défice na população de... de... de... alfabetismo e então eu acho que o Graal teve vários projetos. [...] Fizeram essas reuniões, assim ao 
ar livre e as pessoas, se calhar, aderiram, não sei. Eu na altura não me meti logo, eu na altura não fiz parte logo dos primeiros grupos. (A2, 2012).

Andavam vários estudantes de várias faculdades. Eles vieram para cá muito antes. Andavam ali, até trouxeram tendas, fizeram acampamento e andavam a trabalhar com as pessoas no campo. Abriram estradas, aquela estrada lá em cima... Abrir estradas também já foi posterior ao 25 de Abril, portanto, depois eu também já andei. Tenho lá fotografias disso... Mas dessa primeira fase, desses estudantes que vinham para cá até de alguns estrangeiros que tinham aí umas tendas, que foi a tropa que emprestou e isso [...]. $(A 3,2012)$.

Foi, igualmente, evidente no decurso das entrevistas realizadas que, pesem os receios iniciais, os níveis globais deinteresse e empenhamentoforam muito elevados.Ao proceder à revisão de atividades e dinâmicas existentes, as/ os entrevistadas/as procederam, por iniciativa, à sistematização das principais mais-valias deste projeto, salientando as oportunidades de enriquecimento e desenvolvimento que esta participação permitiu a todos/as aqueles/as que nela colaboraram, seja enquanto aprendentes ou formadores.

Eu não aderi logo. Comecei a ver... Comecei a ter mais conhecimento... era com esses jovens. E depois eu comecei também a entrar, e entrámos, entrei também no grupo. [...]. Convidaram-me para ir la a Coimbra para ver e eu gostei. E depois ai já começaram a entrar outras pessoas do Graal. Lembra-me de fazer reuniões. Naquela altura, era uma novidade, não é? Falar-se sobre sexualidade e foram lá professores falar sobre a sexualidade e tudo assim tão à vontade. Naquela altura, está a ver... Hoje já não é, mas naquela altura era um tabu falar-se nisso. Eu achei aquilo tão... tão espontâneo, tão bem explicado pelas pessoas que, pronto, comecei a entrar... que, realmente, aquilo realmente era interessante. (A 1, 2012).

Pelo impacto destas experiências na sua vida e na vida das comunidades, sentido naquela época e ainda hoje assumido, este projeto de educação de adultos é apontado como uma experiência educativa em pleno, capaz de mobilizar volitivamente todos/as aqueles/as que nele se envolveram, num processo de educação distinto das restantes modalidades existentes (para crianças 
e jovens ou para adultos). Conscientes de que o processo de alfabetização em adultos/as não poderia limitar-se à aprendizagem da leitura e da escrita, ressalvam, na descrição efetuada, as dimensões de promoção cultural e conscientização política, inerentes à vasta maioria das iniciativas desenvolvidas. Associam-the preocupações de promoção do crescimento pessoal, enquanto cidadãos/ãs interventivos/as e conscientes da sua própria história e, também, do desenvolvimento comunitário.

Também participei no teatro.... Era aquele teatro, assim espontâneo, que era, como é que era... os Autos da Barca e essas coisas todas, Gil Vicente. Foi muito bom. Era um tempo de, sei lá... para nós foi um tempo de mudança e um tempo de criatividade. (A2, 2012).

Também se cantavam aquelas canções que na altura não se podiam, não é? Que eram aquelas 'Ei-los que partem', que eram do Zeca Afonso. Aquelas que diziam, como é que é... [...]. Tudo isso, pronto, que nos começou a dar sentido porque até ali a gente andava sem... mas ali comecei a tomar assim um bocado de conhecimento, está a perceber? (A3, 2012).

As pessoas reuniam e depois cada pessoa dava a sua opinião. $(A 1,2012)$.

A maior parte dos/as participantes envolveu-se, como referido,em atividades educativas de teor informal e não formal, nas quais se incluíam tertúlias, discussões guiadas e debates, grande parte das quais desenvolvidas por mulheres na altura implicadas no movimento do Graal.

Lembro-me que tínhamos uma grande mulher, que já morreu, que era a Maria de Lurdes [Pintassilgo] e que ela começou a ir lá também fazer debates, em que estavam também grandes mulheres também lá de Coimbra como a..., uma delas... lembro-me dessa senhora, não sei se já morreu, a esposa do senhor Barbosa de Melo, e outras mais. [...] Naquele círculo de pessoas que vinham ouvilas, e os debates e havia gente académica, gente do Graal, gente de todas as áreas. (A2, 2012).

Veja-se, a este respeito, o relato de uma entrevistada sobre a importância do Graal no âmbito da emancipação das mulheres, no qual destaca, não só a centralidade desta questão no âmbito do projeto e, em oposição, as 
reações negativas de alguns elementos do género masculino, que procuraram, com recurso à violência, reprimir a livre expressão destas mulheres,

Graal para mim é um movimento que nasceu com mulheres católicas, não é? E que naquela altura, antes do 25 de Abril, falar-se das mulheres... [...]. Quando estávamos nas aulas, um dia fomos convidadas por uma jornalista [...] para irmos fazer um debate ao Porto, e fomos ao Porto, eu e uma senhora dos Gatões... bem eramos várias e fomos ao debate e quando estávamos a sair dos estúdios do Porto fomos agredidas pelos homens. 'Que enquanto houver homens, as mulheres não cantam?'... era assim coisas que não se podia... Foram lá para nos bater mesmo. E ela era uma mulher que já estava a promover a igualdade, está a perceber? Não podia haver esta diferença entre os homens e as mulheres, portanto era já uma luta que se estava a travar. (Al, 2012).

No Graal implementou-se uma abordagem em tudo oposta às políticas e práticas educativas repressivas e culturalmente condicionadas que existiam na década de 70 no nosso país, e que se materializavam em elevadas taxas de analfabetismo, particularmente sentido nas zonas rurais.

Chamava-se a escola da amizade. A gente entre si, aquilo era tudo discutido e era muito bonito. Foi porque vínhamos de uma escola... eu vinha de uma escola que não gostei, que era a escola da porrada, da reguada. E ali não, era tudo... tudo discutido, tudo democraticamente... Naquela altura ainda não se falava na democracia, ainda estávamos no pleno regime fascista, não é? Mas já havia a tal abertura marcelista que eu acho que deu alguma abertura, já grande, ao programa que nós fazíamos. O V. não se lembra disto, mas lembra-se que vinham vários estudantes e cantávamos ali nas ruas, tocavam viola... Isto era uma festa. (A2, 2012).

Assente em premissas distintas das ofertas educativas predominantes, em que se procurava uma reprodução das abordagens utilizadas com as crianças e jovens, os conteúdos e as metodologias ajustavam-se às experiências, necessidades e interesses dos/as adultos que o frequentavam e centravam-se na procura de uma educação libertadora, centrada na vida e para a vida.

Não havia só debates a nível da igreja. Lembro-me de grandes poetas que... O Miguel Torga... ĺamos lá e fazíamos leituras e 
depois debatia-se aquelas coisas. Ele uma vez participou, que eu estive lá e participou. Outra que era... também morreu, que era uma grande escritora... como é que se chamava... a Sofia de Mello Breyner... e elas iam e partilhavam aquilo tudo. Era assim um conhecimento geral. (A1, 2012).

Assumido pelos adultos/as que integravam as atividades e por aqueles/as que eram responsáveis pela sua implementação, o compromisso de promoção de processos verdadeiramente transformativos, associado a maior rapidez e facilidade no processo de aprendizagem da leitura e escrita, são tidos como mais-valias da utilização do método Paulo Freire ${ }^{8}$. Num esforço de recordação das especificidades do método, uma das entrevistadas referiu:

Sei que era um método novo que foi aqui implementado e que era uma maneira mais fácil das pessoas aprenderem a ler e a escrever e a terem, portanto... Não tinha nada a ver com o que se aprendia na escola, quando andávamos na escola e fossemos ter com um professor para aprender a ler. Era um método muito mais eficaz, muito mais... Que as pessoas aprendiam a ler com muito mais facilidade. Era aquilo que eu ouvia dizer. (A2, 2012).

As pessoas gostavam [...] as pessoas iam e vinham sempre todas animadas porque aprendiam... [...] começaram logo a saber fazer o nome a saber fazer as contas, que só eles sabiam fazer de cabeça, mas começaram a conhecer os números e a saber juntar e assim... Aquilo que eu ouvia era isso, que pensavam que era muito mais difícil, que vinham a contar que era uma coisa muito mais complicada e que aquilo que até era muito mais fácil. (A I, 20121 .

Para além de recordarem momentos diversos em que refletiam criticamente sobre si e o mundo, num esforço coletivo de análise crítica da sua própria realidade, os/as inquiridos/as salientam que esta transformação não se limitou às mulheres e homens que nela participaram, tendo sido estendidas as reflexões a outros membros da comunidade. Assim, pesem os constrangimentos existentes (e.g., implicava viagens recorrentes de Coimbra a Almalaguês, alguns membros da localidade manifestaram posições contrárias à sua implementação), as narrativas destes quatro adultos denotam uma perspetiva muito positiva em relação ao projeto, não só evidente pela elevada satisfação que revelam, mas também pelas aprendizagens que descrevem ter efetuado. 
No princípio as pessoas aderiram bem. Outras começaram a dizer... Na altura, está a ver, estávamos noutro regime, as pessoas começaram a tremer. Porque vinham também os estudantes e os estudantes... Isto já foi aqui uma abertura e acho que já foi uma preparação para o 25 de Abril porque já se cantavam canções... Eu lembro-me de 'venham mais 5' que eles cantavam com a viola por aqui. Toda a gente cantava. (A2, 2012).

As pessoas aceitaram bem, porque além disso [debates] havia festa, as pessoas cantavam e dançavam e iam às aulas. (A3, 20121 .

As pessoas que nessa altura tinham 40 ou 50 anos não entravam muito nessas atividades... Eram mais os jovens. [...] Jovens e adultos, também houve adultos que tiraram a $4^{a}$ classe lá. (A 1, 2012).

Isto foi tudo muito bem recebido [em Almalaguês]. Bem... Se calhar não foi tão bem recebido por algumas pessoas. (A3, 201 2).

Ainda hoje apontam, como dimensão estruturante, a importância que este projeto teve no incremento da sua conscientização política, na sua assunção de que eram/são adultos/as decisores e comprometidos com o desenvolvimento das comunidades a que pertencem, sendo a sua participação nas ações educativas e culturais tida como um privilégio que em muito contribuiu para a sua identidade enquanto adulto/a e cidadão/ã.

Acho que foi a primeira...em Portugal não sei, mas aqui em Coimbra, da democracia participativa. Depois começamos a fazer reuniões, os jovens, já, incluindo com elas [elementos do Graal], nos vários lugares da Freguesia e depois também para escolher o representante. Onde eram debatidos os problemas da terra. (A 1, 2012).

Era uma escola boa. [...] Era um ambiente mesmo familiar e, por isso é que, muitas pessoas... Houve muitas que não, mas por exemplo, eu e a C. e outras, ficamos sempre... Muito daquilo que 
sou hoje, eu devo ao Graal. Mesmo a minha formação moral e Cristã, isso eu reconheço que devo ao Graal. Mesmo, até, a nível intelectual, quer dizer... Devo isso ao Graal. (A2, 2012).

Assim, mais do que uma experiência circunscrita no espaço e no tempo, a participação nas atividades do Graal e, em específico, nas iniciativas de alfabetização de adultos constituiu para estes entrevistados uma oportunidade única de melhoria das circunstâncias de vida, num contexto social e histórico repressivo. Impelidos/as a encontrar alternativas que concorressem para a melhoria das suas condições de vida, motivados para a aprendizagem da leitura e da escrita, e convictos/as que a partilha e discussão de experiências, perspetivas e vivências são essenciais ao progresso, estes/as adultos/as assumiram um compromisso que se mantém à atualidade.

\section{Conclusão}

Das primeiras experiências do Método Paulo Freire em Portugal releva a centralidade que este programa educativo, integrado nas iniciativas que o 80 Graal desenvolveu na região rural do concelho de Coimbra, no âmbito da alfabetização de homens e, essencialmente, de mulheres adultos/as e na transformação que estes e estas vivenciaram na sua leitura de si mesmos/as e do mundo. Quase meio século depois mantém memórias detalhadas das experiências vividas e das aprendizagens efetuadas, às quais atribuem particular significado, dado terem ocorrido em tempos de restrições sociais, em que já se antecipavam mudanças de paradigma governativo. As ferramentas que adquiriram neste processo foram, de acordo com as perspetivas dos/as próprios, vitais para a promoção de uma vida melhor. Por um lado, porque as aprendizagens se consubstanciavam nas suas necessidades e interesses mais profundos e, por outro, porque, não se restringiu à componente de Alfabetização em si, tendo envolvido um processo de enriquecimento pessoal e social, essencial para uma participação ativa e responsável na comunidade e na sociedade. No que respeita, em concreto, à participação em atividades de educação de adultos, as memórias descrevem este projeto de alfabetização como uma iniciativa imprescindivel para a população em causa, a qual se pautou por premissas assaz distintas das abordagens tradicionais. Em completa oposição com a "Escola da porrada", epiteto que uma das entrevistadas utilizou para 
caracterizar a escola tradicional, na "Escola da amizade" todos/as tinham liberdade para expor a sua opinião e podiam aprender a ler e escrever segundo o seu ritmo e interesses, num contexto de aprendizagem em que se refletia sobre cada um/a e o mundo. Esta dimensão, de aumento da reflexão crítica e participação social, é, sem dúvida, um dos elementos a que os/as entrevistados/as conferem destaque, não só porque traduzia uma diferença substantiva em relação à aprendizagem formal da época, mas também porque the atribuíram particular significado e, ainda hoje, a associarem a uma transformação significativa nas suas conceções de si e do mundo, a qual foi tendo repercussões efetivas no decurso das suas vidas.

Tal como era enunciado pelo Graal, nos seus documentos oficiais, o objetivo deste conjunto de atividades orientava-se no sentido de proporcionar uma tomada de consciência das mulheres e da sua força coletiva, contribuindo, com uma nova forma de estar na vida, para uma maior humanização da sociedade portuguesa. Naquele momento e naquela fase da vida política e social daquela comunidade, as experiências consubstanciadas na "Escola da Amizade" parece terem cumprido o essencial desse desejo, contribuindo decisivamente para que o movimento se sentisse próximo da expressão usada para traduzir a universalidade do espírito que o animava e que dava título a um livro de uma australiana, considerada como uma das suas ativistas mais empenhada: I belong where i am needed.

Neste processo, tal como é reconhecido por todos os envolvidos, o recurso ao pensamento e práticas de Paulo Freire revelou-se perfeitamente ajustado, quer ao nível dos fins prosseguidos, quer dos meios para os atingir. Esta convicção dos envolvidos, que traduz um resultado de verdadeira propensão de homens e mulheres para serem mais e aprofundarem o seu processo humanizador, tornando-se mais capazes de ações concretas fundadas em pequenas buscas indutoras de maior igualdade de direitos e superação de algumas injustiças ancestrais.

\section{Notas}

1 Como podemos verificar na publicação sobre os primeiros vinte e cinco anos de atividades do movimento (GRAAL, 1983), já tinham sido desenvolvidas atividades de alfabetização, nos anos imediatamente anteriores, no distrito de Portalegre, utilizando alguns princípios de aprendizagem da leitura e da escrita, com base nas propostas de Paulo Freire. Como veremos de seguida, esta 
experiência de Coimbra, em 1970, e tal como é entendida pelas/os intervenientes, tem caraterísticas muito diferentes e, por isso mesmo, nos parece a primeira experiência portuguesa que junta diferentes práticas, com um planejamento e desenvolvimento a partir de uma apropriação e adequação local do pensamento e das práticas do grande educador brasileiro.

2 É importante recordar que Portugal vivia, há mais de quatro décadas, numa ditadura que proibia o exercício da generalidade dos direitos básicos e mantinha, em África, uma guerra de três frentes que implicava a participação compulsiva de todos os jovens do sexo masculino, a partir dos vinte anos.

$3 \bigcirc$ essencial desta tese é afirmada na entrevista que Maria de Lurdes Pintassilgo concedeu a António Teodoro (2002) para o livro As Políticas de Educação em Discurso Directo. Também António Barbosa de Melo, na entrevista que nos concedeu, para este artigo, confirma a versão, dando conta das conversas com o bispo de Coimbra para a instalação do Graal na diocese. Mais tarde, já na segunda metade da década de sessenta, o Cardeal Patriarca de Lisboa acabou por reconhecer o mérito da ação do Graal, exortando as suas responsáveis a instalar-se na capital.

4 Estágios de Alfabetização e Animação Social, segundo a metodologia de Paulo Freire, programa e textos de apoio à semana de preparação para os animadores e alfabetizadores, que decorreu em Coimbra, entre 1 e 7 de Agosto de 1970, disponível em:http://www.fcuidarofuturo.com.

5 Como poderemos verificar no documento citado (GRAAL, 1970), participaram na Equipa de Apoio Técnico como Formadores/Animadores das sessões deste estágio, para além das dirigentes nacionais e locais do Graal, os Docentes da Faculdade de Direito António Barbosa de Melo e Manuel Porto e, como convidado, o Professor Fernandes Martins, da Faculdade de Letras, que tinha concluído uma Tese de Doutorado sobre Orio Mondego e as suas gentes.

6 Uma das questões que nos inquietava quando iniciámos este trabalho de pesquisa relacionava-se com as razões para a escolha daquelas aldeias (Almalaguês, Cabouco e Dianteiro) em particular. Para além da sua identidade bem rural, marcada por uma agricultura de subsistência, na verdade, elas tinham características bem distintas: Almalaguês era conhecida pelo seu artesanato, com recurso a teares ancestrais; Cabouco pela sua situação junto ao rio Mondego; Dianteiro por se situar na parte mais montanhosa dos arredores de Coimbra. Para além de nos parecer que houve uma ligação preferencial ao clero da região que melhor poderia aceitar estas iniciativas, também fica claro na entrevista que António Barbosa de Melo nos concedeu que haveria entre algumas habitantes das aldeias e as estudantes algumas relações de conhecimento. Nos casos de Almalaguês e Dianteiro esse conhecimento seria motivado pela venda de tapeçarias e produtos agrícolas, no caso do Cabouco seria a prestação de serviços como lavadeiras aos/às estudantes que teria facilitado esse conhecimento.

7 Na entrevista que nos concedeu para este trabalho, António Barbosa de Melo, apenas recorrendo à memória, reafirma o essencial do que escreveu neste texto, quarenta e dois anos antes. Na sua interpretação, a pedagogia de Paulo Freire era particularmente indicada para preparar uma mudança social, na qual as pessoas fossem os verdadeiros sujeitos, resistindo, em termos teóricos e práticos à inculcação exterior de saberes e ideologias. Na entrevista a A. Teodoro, Maria de Lurdes Pintassilgo deixa antever um entendimento muito congruente com estas orientações gerais.

8 O/as participantes nesta pesquisa referiram lembrar-se da visita de Paulo Freire a Almalaguês, logo a seguir à revolução portuguesa de 1974. Não conseguiam, no entanto, descrever esse momento de forma circunstanciada, uma vez que era um período em que diferentes acontecimentos 
se sucediam, numa enorme vertigem. Paulo Freire deixou-nos na Pedagogia da Esperança (FREIRE, 1992) a sua opinião muito abonatória sobre este trabalho do Graal e sobre a sua visita á região rural de Coimbra para contactar com os ex-alfabetizandos/as.

\section{Referências}

ALCOFORADO, Luís. Educação de adultos e trabalho. 2000. $217 f$. Dissertação (Mestrado em Educação) - Faculdade de Psicologia e de Ciências da Educação, Universidade de Coimbra, Coimbra, 2000.

modelo da competência e os adultos portugueses não qualificados. Revista Portuguesa de Pedagogia, Coimbra, v. 35, n. 1, p. 67-83, jan./abr. 2001.

A educação de adultos como contributo para uma vida com mais direitos e oportunidades. Conselho Nacional de Educação. Educação e direitos humanos. Lisboa: CNE, 2004.

ALCOFORADO, Luis; FERREIRA, Sónia Mairos. Educação e formação de adultos: nótulas sobre a necessidade de descomprometer a Cinderela depois do beijo do Príncipe Encantado. In: ALCOFORADO, Luís e Outros. Educação e formação de adultos. Políticas, práticas e investigação. Coimbra: Imprensa da Universidade de Coimbra, 2012.

A1. Entrevista oral. Almalaguês (Portugal), 04 out. 2012.

A2. Entrevista oral. Almalaguês (Portugal), 04 out. 2012.

A3. Entrevista oral. Almalaguês (Portugal), 02 out. 2012.

BARRETO, António; PRETO, Clara Valadas. Indicadores sociais: Portugal, 1960-2000. In: BARRETO, António (Org.). A situação social em Portugal (1960-1999). Lisboa: Imprensa de Ciências Sociais, 2000. (v. II).

CANDEIAS, António; PAZ, Ana Luísa; ROCHA, Melânia. Alfabetização e escola em Portugal nos séculos XIX e XX. Os censos e as estatísticas. Lisboa: Fundação Calouste Gulbenkian, 2004.

CARVALHO, Rómulo. História do ensino em Portugal desde a fundação da nacionalidade até ao fim do regime de Salazar-Caetano. Lisboa: Fundação Calouste Gulbenkian, 2011.

CARVALHO, Vicente Vitoriano Marques de. As imagens no "Método Paulo Freire" na Experiência de Angicos. Revista Educação em Questão, Natal, v. 21 , n. 7, p. 98-1 15, set./dez. 2004. 
FREIRE, Paulo. Educação como prática da liberdade. Rio de Janeiro: Paz e Terra, 1984

Pedagogia da esperança. Um reencontro com a Pedagogia do Oprimido. São Paulo: Paz e Terra, 1992.

Cartas a Cristina. São Paulo: Editora Unesp, 2002.

GRÁCIO, Rui. Ensino primário e analfabetismo. In: SERRÃO, J. Dicionário de História de Portugal. Porto: Portucalense, 1981.

GRAAL. Portugal. Graal, 25 anos de história. Lisboa: Edições Graal, 1983.

Boletim Mudar a Vida, Lisboa, n. 19, p. 1, jul./ago. 1979.

Alfabetização e animação social, Coimbra, verão 70. Fundação cuidar o futuro. Arquivo Pintassilgo. Disponível em: http://www.fcuidarofuturo.com. Acesso em: 10 set. 2012.

PATRÍCIO, Manuel Ferreira. A educação de adultos em Portugal. In: Educação de Adultos no Alentejo, contributo para a formação dos agentes educativos. Évora: Universidade de Évora, 1982.

84 PORTUGAL. Decreto-Lei n 38.968 de 27 de outubro de 1952. Diário do Governo, Lisboa, 1952.

TEODORO, António. As políticas de educação em discurso directo: 1955-1995. Lisboa: Instituto de Inovação Educacional, 2002.

TORGAL, Luís Reis. A instrução pública. In: MATTOSO, José. História de Portugal. Lisboa: Círculo de Leitores, 1993. (v. V).

RUAS, Henrique Barrilaro. Educação de adultos em Portugal, no passado e no presente. In: GUSMÃO, Maria José; MARQUES, António Gomes (Org.). Educação de adultos. Braga: Universidade do Minho, 1978. 
Prof. Dr. Luís Alcoforado

Universidade de Coimbra

Faculdade de Psicologia e de Ciências da Educação Grupo de Políticas Educativas e Dinâmicas Educacionais E-mail | lalcoforado@fpce.uc.pt

Ms. Sónia Mairos Ferreira

Universidade de Coimbra

Faculdade de Psicologia e de Ciências da Educação Grupo de Políticas Educativas e Dinâmicas Educacionais E-mail | smairosferreira@fpce.uc.pt

Recebido 09 out. 2013 Aceito 16 dez. 2013 